\title{
Elastic response of a light-weight floating support structure of FOWT with guywire supported tower
}

\author{
Hideyuki Suzuki ${ }^{1}$ (D) Jiang Xiong ${ }^{2} \cdot$ Lucas H. S. do Carmo $^{3}$. Daniel P. Vieira ${ }^{4} \cdot$ Pedro C. de Mello $^{3} \cdot$ Edgard B. Malta $^{4}$. \\ Alexandre N. Simos ${ }^{3}$. Shinichiro Hirabayashi ${ }^{1} \cdot$ Rodolfo T. Gonçalves ${ }^{1}$
}

Received: 3 September 2018 / Accepted: 28 November 2018 / Published online: 8 December 2018

(c) The Author(s) 2018

\begin{abstract}
To obtain fundamental knowledge on the elastic response characteristics of a light-weight floating support structure of a FOWT (floating offshore wind turbine) with guywire supported tower, basic load transmission mechanism was investigated. Static analysis with elastic frame model, numerical analysis and wave tank experiment with elastically and dynamically similar segmented backbone model were conducted to clarify the dynamic elastic response characteristics of the structure. In the numerical analysis, analysis code of a rotor-floater-mooring-control coupled response NK-UTWind developed in University of Tokyo is used. It is clarified that when the rigidity of the frame structural part is low compared with guywire, the load is mainly borne by guywire under pitch motion. It was found that the tension fluctuation of guywire becomes large at wave period of $6 \mathrm{~s}$ when the inertial force due to pitch motion is large, and at wave period of 18-20 s when inclination of tower is larger the tension fluctuation also becomes large due to the overturning moment.
\end{abstract}

Keywords FOWT $\cdot$ Floating support structure $\cdot$ Guywire $\cdot$ Elastic response $\cdot$ Elastic model

\section{Introduction}

Concerning floating offshore wind turbines, demonstration of technological feasibility by domestic technology is under way in Japan, and floating offshore wind turbines of real scale are operated in real sea. One project is Fukushima Wind Farm Project [1] supported by the Ministry of Economy, Trade and Industry, another is Project of Kabashima of Goto Archipelago [2] supported by Ministry of the Environment. Following these experiences, the next generation floating offshore wind power generation system demonstration research by NEDO (barge type) [3], was initiated aiming for further cost reduction. Studies are focused on commercialization and new floating type, mooring system, installation and construction technologies are investigated.

\footnotetext{
Hideyuki Suzuki

suzukih@sys.t.u-tokyo.ac.jp

The University of Tokyo, Tokyo, Japan

Works Applications Co., Ltd., Tokyo, Japan

University of São Paulo, São Paulo, Brazil

4 Technomar Engenharia Oceânica, São Paulo, Brazil
}

For development of low cost concept of floating support structure, a design with guywire supported tower has been proposed [4]. This type is a light-weight semi-submersible type floating structure and requirement for tower strength which is stringent in conventional design is much relieved by the use of guywire in particular at the base of the tower. While this floating type is expected to be considerably lighter, elastic response due to wind and waves may be increased due to a decrease in rigidity, and this may have an effect on the mooring system. In addition, the elastic response is an important point of interest regarding the feasibility of guywire system. The load due to wind and wave is transmitted to the columns and pontoon through the frame structure comprised of tower and pontoons and also the guywire system, and the loads are finally balanced with the buoyancy change of the columns and equilibrium condition is established.

Tension of the guywire and the internal force of tower and pontoons are determined by the load transmission mechanism. It is necessary to clarify how rigidities of tower, pontoons and guywire affect the load transmission and dynamic response characteristics.

Guywire is used in a cable-stayed bridge. The elastic response is studied using a cable / beam model [5] but in the 
case of a cable-stayed bridge, there is no rigid body motion of the whole structure. Motion of the whole structure has significant effect on the structural response of the floating offshore wind turbine. In this study, basic load transmission mechanism is investigated using static elastic model firstly, and wave tank experiment with elastically similar model are conducted to clarify the dynamic elastic response characteristics of the floating support structure. The experimental results are then compared with numerical analyses.

In the design of a floating offshore wind turbine, it is necessary to discuss coupled response with a wind turbine equipped with nonlinear control, basically it is necessary to use a time domain rotor-floater-mooring-control coupled analysis code. It is necessary to evaluate the structural internal forces in the structural design. As an analysis method, there is a two-step solution method that separately evaluates the rigid body motion and structural response. In the another method, a one-step solution method, a floating offshore wind turbine is modeled as an elastic body, and the structural response is solved simultaneously with the rigid body motion movement. FAST developed at NREL has a function to solve the wind turbine and tower by modeling it as an elastic body and obtain the tower base moment, which is an intermediate analysis method between a one-step solution method and a two-step solution method [6]. One-step solution method using Morison equation which can evaluate diffraction and radiation force of a slender member relatively precisely, has been developed for design of a floater with relatively small hydrodynamic interaction between elemental members of the floater [7, 8]. As a two-step solution method, a method has been developed for design of a barge type floating offshore wind turbine. The multibody method is adopted in the method. Wave load, added mass coefficients and radiation damping coefficients are evaluated using potential theory modeling the floater as a rigid body by fixing the relative position of the multi-bodies. The results are arranged as a database and referring to it, the elastic response of the floater is analyzed [9]. In this research, the fluctuation of the guywire tension due to the elastic deformation is discussed. A one-step solution method in the time domain, specifically NK-UTWind is used.

\section{Generalized model for analysis}

The assumed floating support structure is a light-weight FOWT with guywire supported tower moored by single point mooring system and yaw mechanism is thus abolished [4], but since the shape is complicated, such as the inclination of the tower with different length of guywires, a generalized model was designed extracting general features of the guywire supported structure. The generalized model has a vertical guywire

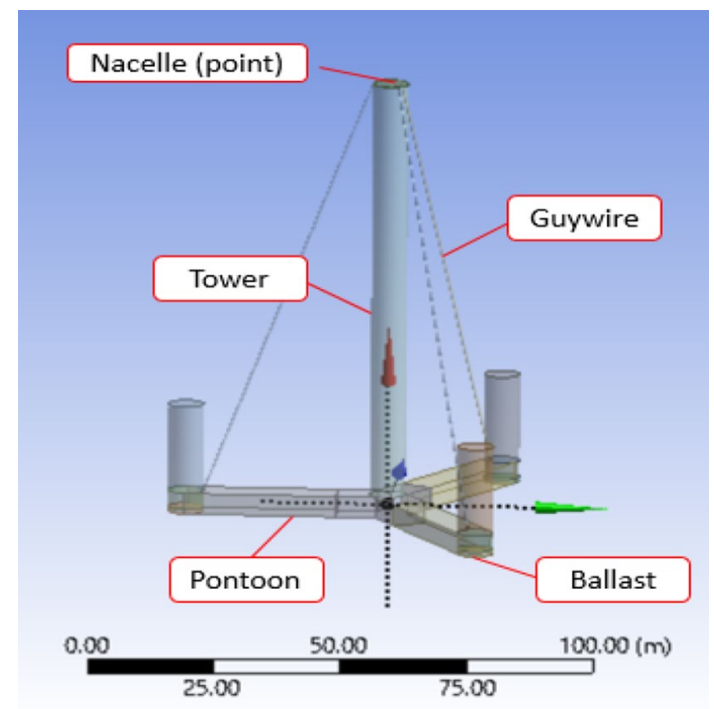

Fig. 1 Generalized floating support structure

Table 1 Principal parameters of generalized floating support structure

\begin{tabular}{ll}
\hline Item & Prototype \\
\hline Displacement (ton)] & 5774 \\
$\mathrm{~KB}(\mathrm{~m})$ & 4.59 \\
$\mathrm{BM}(\mathrm{m})$ & 16.08 \\
$\mathrm{KG}(\mathrm{m})$ & 8.31 \\
$\mathrm{GM}(\mathrm{m})$ & 12.36 \\
Natural period of heave (s) & 16.6 \\
Natural period of roll and pitch (s) & 20.6 \\
Flexural rigidity of pontoon $\left(\mathrm{N} \mathrm{m}^{2}\right)$ & $2.707 \mathrm{E} 11$ \\
Flexural rigidity of tower $\left(\mathrm{N} \mathrm{m}^{2}\right)$ & $5.031 \mathrm{E} 11$ \\
Tower height (m) & 102.35 \\
Horizontal distance from tower center to guywire connec- & 33.0 \\
tion point (m) & \\
Guywire length (m) & 107.54 \\
\hline
\end{tabular}

supported tower as shown in Fig. 1 and principal parameters concerning the rigidity and dynamics of the model are tabulated in Table 1.

\section{Load transmission mechanism}

A two-dimensional static elastic model was set up to analyze and clarify the load transmission mechanism in the floating supporting structure with guywire.

\subsection{Static structural model and equilibrium equation}

To grasp the influence of axial rigidity of guywire and bending rigidity of tower and pontoon on the guywire tension, 
structural members are modeled as follows. Tower and pontoon are modeled as beam, guywire is modeled as spring, buoyancy change of corner columns due to rigid body inclination and elastic deformation of the structure is modeled as a buoyancy spring. The two-dimensional static elastic model is shown in Fig. 2. The parameters $\Delta, \delta_{1}$ and $\delta_{2}$ are rigid body displacements and elastic deflections combined values. Exact solutions can be obtained for this model. For the case where the horizontal load is applied at the top of the tower, the change of tension of the guywire from the static equilibrium state under initial tension is obtained as a function of the spring constant of the guywire and bending stiffness of the tower and the pontoon as given in Eq. 1.

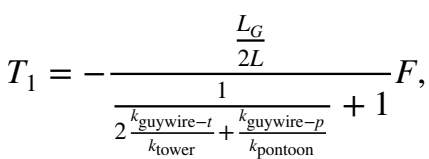

where $F$ is the horizontal external force acting at the top of the tower, $L$ is the length of the pontoon, $L_{\mathrm{G}}$ is the length of the guywire, and $T_{1}$ and $T_{2}$ are the changes of guywire tensions from initial tensions, respectively. $k_{\text {tower }}$ is the horizontal spring constant of tower when the base of the tower is fixed, and $k_{\text {guywire }-t}$ is the spring constant of the guywire in the horizontal direction and $k_{\text {guywire }-p}$ is spring constant of guywire in vertical direction, respectively, and $k_{\text {pontoon }}$ is the spring constant of pontoon in the vertical direction when the root of the pontoon is fixed. The expression for $T_{2}$ is obtained by changing sign of load in Eq. (1). The values are given as follows.

$k_{\text {tower }}=\frac{3 \mathrm{EI}_{\mathrm{T}}}{H^{3}}$, $k_{\text {guywire }-t}=k_{\mathrm{G}}\left(\frac{L}{L_{\mathrm{G}}}\right)^{2}$,

$k_{\text {guywire }-p}=k_{\mathrm{G}}\left(\frac{H}{L_{\mathrm{G}}}\right)^{2}$,

$k_{\text {pontoon }}=\frac{3 \mathrm{EI}}{L^{3}}$,

where $H$ is the tower height, $\mathrm{EI}_{\mathrm{T}}$ is the tower bending stiffness, $\Delta$ is the horizontal displacement of the tower, EI is the pontoon bending stiffness, $\delta_{1}$ and $\delta_{2}$ are the vertical displacement of the columns, $\delta$ is the vertical displacement of the tower base column, $k_{\mathrm{G}}$ is the guywire spring constant. $\theta$ is the rotation angle (rigid body rotation angle) at the connection point of tower base and root of the pontoons.

The change of the guywire tension when the sagging and hogging load acts on the floating structure is similarly given by the Eq. (6).

$T=\frac{-\frac{L_{\mathrm{G}}}{H}\left(\frac{k F_{\mathrm{B}}-k_{\mathrm{B}} F}{k+2 k_{\mathrm{B}}}\right)}{\frac{k_{\text {pontoon }}}{k_{\text {guywire }-p}}+\frac{k k_{\mathrm{B}}}{\left(k+2 k_{\mathrm{B}}\right) k_{\text {guywire }-p}}+1}$,

where $k_{\mathrm{B}}$ is buoyancy spring of column, $k$ is buoyancy spring of tower base column, $F_{\mathrm{B}}$ and $F$ are vertical force acting on column and center column respectively.
Fig. 2 Static structural model in the case where horizontal load acts on top of tower and when sagging/hogging load acts

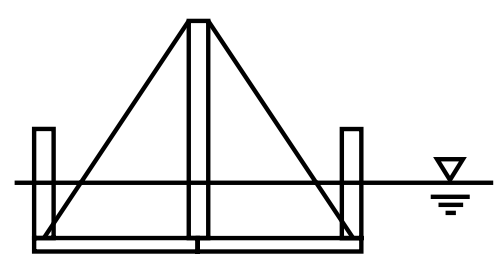

Analysis Model for Horizontal Force Applied at Tower Top

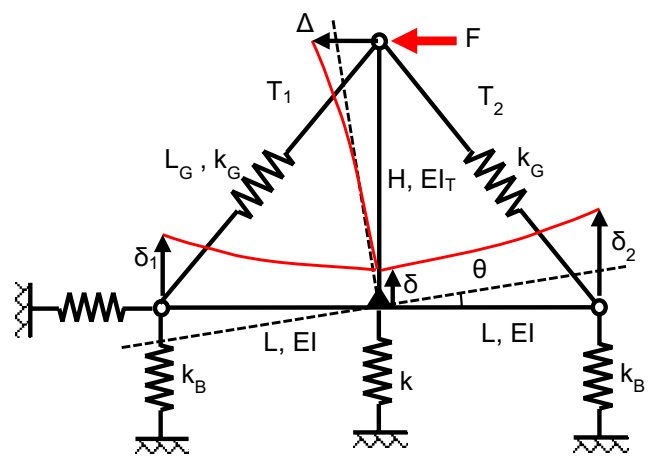

Analysis Model for Sagging and Hogging Loads

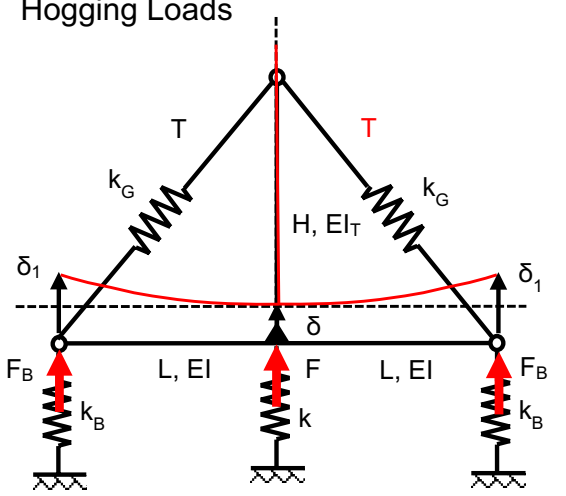




\subsection{Effect of stiffness of each components on load transmission function}

The values of $k_{\text {guywire-t }} / k_{\text {tower }}$ and $k_{\text {guywire- } p} / k_{\text {pontoon }}$ are, respectively, in the order of 30 and 40 for the real structure. Table 2 shows the effect of change of guywire spring constant and bending rigidities of tower and pontoon on the tension fluctuation amplitude of guywire based on the Eq. (1) for the case when horizontal concentrated force due to thrust force of wind turbine and wind load on the tower is applied at the tower top as a concentrated load. The horizontal overturning force is transmitted to columns through the structure and balanced with the buoyancy forces caused by the change of the column submergence due to the inclination and deformation of the floating structure.

When the bending rigidity of either the tower or the pontoon or both is small, the function of load transmission to the column through frame structural part is weak when the force is applied at the top of the tower, and the force is transmitted mainly through guywire and the guywire tension becomes larger. Conversely, when the bending rigidity of both the tower and the pontoon is large, the function of guywire to support the external force decreases, and the tension of guywire decreases.

The values of $k_{\text {guywire-p }} / k$ and $k_{\text {guywire-p }} / k_{\text {pontoon }}$ are, respectively, in the order of 900 and 40 for the real structure. Table 3 also shows the effect of change of guywire spring constant and bending rigidities of tower and pontoon on the tension fluctuation amplitude of guywire based on the Eq. (6) for the case when sagging and hogging load is applied to the columns of floating structure as concentrated forces. When the bending rigidity of the pontoons is large, the deformation of the structural part becomes small, so that the tension of guywire also becomes small. In addition, it can be seen that the tension fluctuation decreases even if the buoyant spring constant of the column is small.

\section{Dynamic response characteristics}

\subsection{Numerical calculation method}

For the analysis of motion and structural response, NKUTWind [7], a Rotor-Floater-Mooring-Control coupled analysis code, is used. In the analysis code, rotor and the floating body are modeled with beam elements, the mooring system is modeled by the lumped mass method. For the calculation of the aerodynamic load acting on the rotor, wind turbine analysis code FAST $[6,10]$ based on the blade element momentum theory (BEM) developed by NREL is used.

Regarding the wave load calculation, extended Morison equation which can evaluate hydrodynamic force even when the cross section of the slender submerged body is a rectangle or an ellipse is used, since the floating support structure is comprised of relatively slender bodies. For the other part of the submerged body, Hooft's method is used. The equations of motion of rotor, floating structure and mooring formulated independently are solved in time domain by Newmark $\beta$ method using weakly coupling method. The response by the negative damping peculiar to the floating offshore wind turbine can also be sufficiently reproduced. NK-UTWind is undergoing code comparative study OC5 (Offshore Code Comparison, Collaboration, Continued, with Correlation project.) $[11,12]$ organized under IEA for comparing and validating analysis codes of floating offshore
Table 2 Influence of bending rigidities of tower and pontoon on tension of guywire
Table 3 Influence of bending rigidities of pontoons and spring constant of buoyancy on tension of guywire

\begin{tabular}{lll}
\hline Tension of guywire, $\left|T_{1}\right|$ & $\begin{array}{l}\text { Ratio of guywire spring constant to tower } \\
\text { bending rigidity, } \frac{k_{\text {guywire }-}}{k_{\text {tower }}}\end{array}$ & $\begin{array}{l}\text { Ratio of guywire spring constant } \\
\text { to pontoon bending rigidity, } \\
\frac{k_{\text {guywire }-p}}{k_{\text {pontoon }}}\end{array}$ \\
\hline Large & Large (flexible tower) & Large (flexible pontoon) \\
Large & Small & Large \\
Large & Large & Small \\
Small & Small & Small \\
\hline
\end{tabular}

\begin{tabular}{lll}
\hline $\begin{array}{l}\text { Tension of guywire, } \\
\left|T_{1}\right|\end{array}$ & $\begin{array}{l}\text { Ratio of guywire spring constant to buoyancy } \\
\text { spring constant, } \frac{k_{\text {guywire }}}{k}\end{array}$ & $\begin{array}{l}\text { Ratio of guywire spring constant } \\
\text { to pontoon bending rigidity, } \\
\frac{k_{\text {guywire- }}}{k_{\text {pontoon }}}\end{array}$ \\
\hline Large & Large (small buoyancy spring constant) & Large (flexible pontoon) \\
Small & Small & Large \\
Small & Large & Small \\
Small & Small & Small \\
\hline
\end{tabular}


wind turbine, and analysis function of the NK-UTWind is validated.

In this research, the analysis function of guywire was added. Taking the deformation of the floating structure as the geometrical boundary condition, tension of guywire is calculated from the change of distance between the support points of the guywire after considering the initial tension, and applied to the structure.

\subsection{Wave tank experiment}

To grasp elastic response characteristics of the floating support structure in waves, a wave tank experiment was conducted using wave tank of University of San Paulo from September 16 to October 28, 2017. In the experiment, following the inclining test and the free-decay test, the regular wave experiment, the transient wave experiment, irregular wave experiment (JONSWAP, white noise) were carried out and the floating body motion, the tension in guywire, strain at tower base and strain in the pontoon were measured

\section{Experimental model}

The model is a $1 / 80$ elastically and dynamically similar segmented-backbone model shown in Fig. 3. In the experimental model, guywires are modeled with three steel wires. The connecting point of the guywire is the root of the pontoon and the top of the tower. As shown in Fig. 4, a beam spring is installed at the top of the tower to realize similarity of the axial rigidity of the guywire, and it also functions as a tension measurement device. A long screw is inserted in the guywire and the

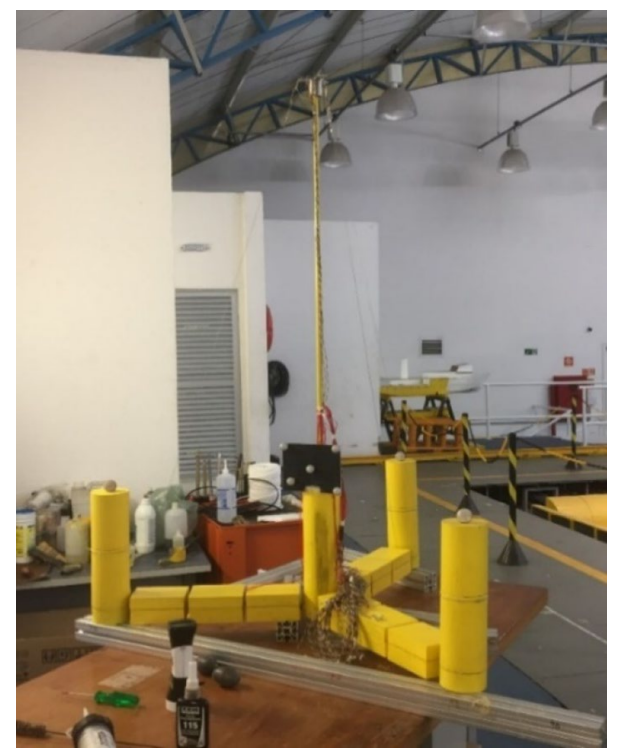

Fig. 3 Elastically and dynamically similar segmented backbone model

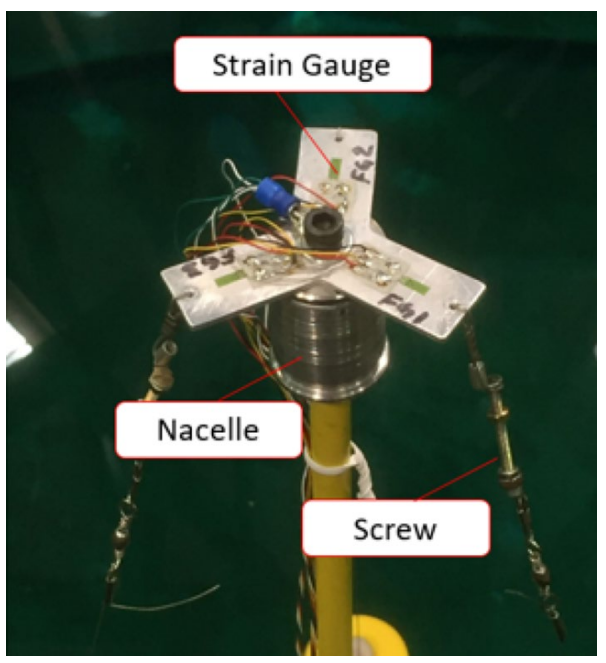

Fig. 4 Measurement device of guywire tension at top of the model

initial tension is adjusted. Principal parameters of the 1/80 elastically similar model and guywire are tabulated in Tables 4 and 5. Mass and inertia similarities are established by making cross sectional dimensions of pontoon and columns similar and adjusting weight to establish similarity of weight distribution. Thus the draft is made similar. Using the parameters, the ratios of spring constants were calculated. The values are $k_{\text {guywire }-t} / k_{\text {tower }}=0.660, \quad k_{\text {guywire }-p} / k_{\text {pontoon }}=0.396$ for real structure and $k_{\text {guywire- } t} / k_{\text {tower }}=38.9$, $k_{\text {guywire }-p} / k_{\text {pontoon }}=27.6$ for experimental model. Denominator of the Eq. (1) is calculated for both real structure and the experimental model. The values are given as follows.

Table 4 Principal parameters of 1/80 elastically and dynamically similar model

\begin{tabular}{ll}
\hline Item & Exp. model (1/80) \\
\hline Displacement $(\mathrm{kg})$ & 11.25 \\
$\mathrm{~KB}(\mathrm{~m})$ & 0.0575 \\
$\mathrm{BM}(\mathrm{m})$ & 0.2016 \\
$\mathrm{KG}(\mathrm{m})$ & 0.1046 \\
$\mathrm{GM}(\mathrm{m})$ & 0.1543 \\
Natural period of heave $(\mathrm{s})$ & 1.86 \\
Natural period of roll and pitch $(\mathrm{s})$ & 2.28 \\
Flexural rigidity of pontoon $\left(\mathrm{N} \mathrm{m}^{2}\right)$ & 82.6 \\
Flexural rigidity of tower $\left(\mathrm{N} \mathrm{m}^{2}\right)$ & 154 \\
Tower height $(\mathrm{m})$ & 1.312 \\
Horizontal distance from tower center to guywire & 0.500 \\
$\quad$ connection point $(\mathrm{m})$ & \\
Guywire length $(\mathrm{m})$ & 1.404
\end{tabular}


Table 5 Principal parameters of guywire

\begin{tabular}{lll}
\hline Item & Prototype & Model (1/80) \\
\hline Material & CFRP & Steel \\
Young's Modulus (Pa) & $1.35 \mathrm{E} 11$ & $2.0 \mathrm{E} 11$ \\
Tensile strength $(\mathrm{MPa})$ & 300 & 400 \\
Safety factor & 3.0 & 3.0 \\
Diameter $(\mathrm{mm})$ & 100 & 1 \\
Sectional area $\left(\mathrm{mm}^{2}\right)$ & 7853.982 & 0.785 \\
Max tension $(\mathrm{N})$ & $7.69 \mathrm{E} 6$ & 98.0 \\
Pretension $(\mathrm{N})$ & $1.96 \mathrm{E} 6$ & 3.82 \\
Spring constant $\left(\mathrm{N} \mathrm{m}^{-1}\right)$ & $9.87 \mathrm{E} 6$ & $6.27 \mathrm{E} 4$ \\
& & Stiffness of cantilever \\
& & strain gauge is con- \\
& & sidered \\
\hline
\end{tabular}

Real structure : $\frac{1}{2 \frac{k_{\text {guywire- } t}}{k_{\text {tower }}}+\frac{k_{\text {guywire }-p}}{k_{\text {pontoon }}}}+1=1.58$,

Experimental model : $\frac{1}{2 \frac{k_{\text {guywire- } t}}{k_{\text {tower }}}+\frac{k_{\text {guywire- }}}{k_{\text {pontoon }}}}+1=1.01$.

The spring constant of the guywire of the experimental model is relatively large, and the load transmission by the guywire is large and the tension is considered to be large. On the other hand, in the real structure, the rigidity of the structural part is relatively large and the load transmission by guywire becomes smaller.

\section{Experimental wave tank}

The experiment was carried out at Ocean Basin of Numerical Test Tank (TPN) of University of San Paulo (USP). Figure 5 shows wave tank and facilities. The basic information of the tank is as follows.

Tank dimension

Wave maker

Wave absorbing ability

$14 \mathrm{~m}$ long $\times 14 \mathrm{~m}$ wide $\times 4 \mathrm{~m}$ deep

Wave frequency range arranged in four side walls

90-98\%

$0.5 \mathrm{~Hz}$ to $1.5 \mathrm{~Hz}$

3. Coordinate system in experiment

Figure 6 shows the plan of the wave tank and the coordinate system and arrangement of mooring. The coordinate system is defined as shown at the bottom left of the schematic diagram, and the motion was measured with four cameras (black square $\mathbf{0}$ ), and three wave height meters (white circle $O$ ) were placed. Numbers 1, 2 and 3 shown on the diagram of the model are reference

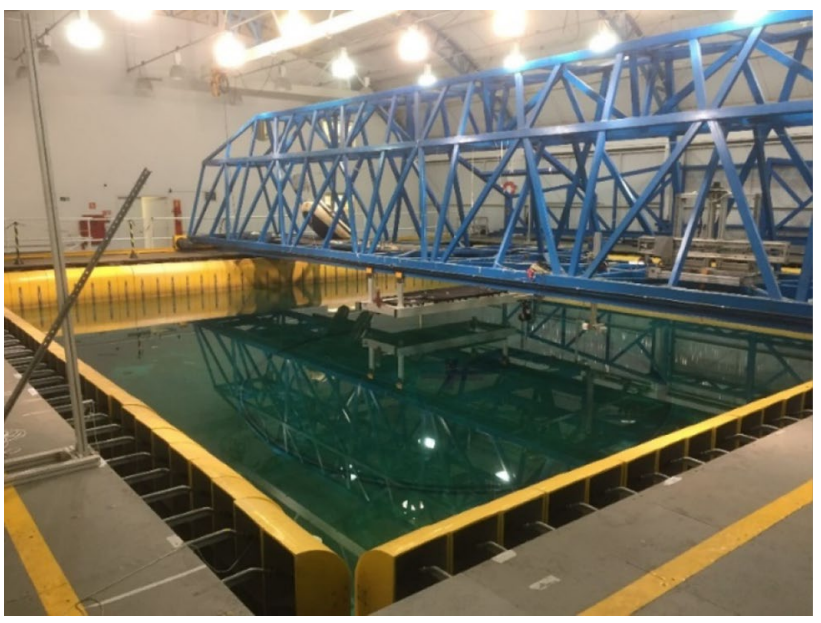

Fig. 5 Ocean Basin of Numerical Test Tank (TPN) of University of San Paulo

numbers of the corresponding columns, pontoons and guywires respectively. Yellow squares are wave makers. Waves are assumed to proceed always in the positive direction of $x$-axis. Five set of mooring points were set on the side wall of the tank and five wave incident angles of $180^{\circ}, 195^{\circ}, 210^{\circ}, 225^{\circ}$ and $240^{\circ}$ were set by changing the anchor points. Each column of the model and the mooring anchor point were connected by a weak spring with a spring constant of $2.2 \mathrm{~N} \mathrm{~m}^{-1}$.

4. Experiment items and experimental parameters

Regular wave test, transient wave test and irregular wave test (JONSWAP, white noise) were carried out after the inclining test and the free-decay test. Measurement items are: (1) motion of 6 degrees of freedom (8 targets), (2) tension fluctuation in the guywire (3 strain gauges), (3) strains at the tower base (3 strain gauges), (4) strains at root and middle of the pontoon (6 strain gauges), and (5) wave height (three wave height meters). The position of the strain gauge and identification number of strain gauge is shown in Fig. 7. Experimental parameters of transient wave experiment, irregular wave experiment and regular wave experiment are as follows.

(1) Transient wave experiment

The transient wave experiment was carried out under the following conditions in terms of real structure scale value where the wave height is constant and the wave frequency is gradually increased.

Wave period range: $6.6-17.9 \mathrm{~s}$.

Wave height: $2.74 \mathrm{~m}$ 

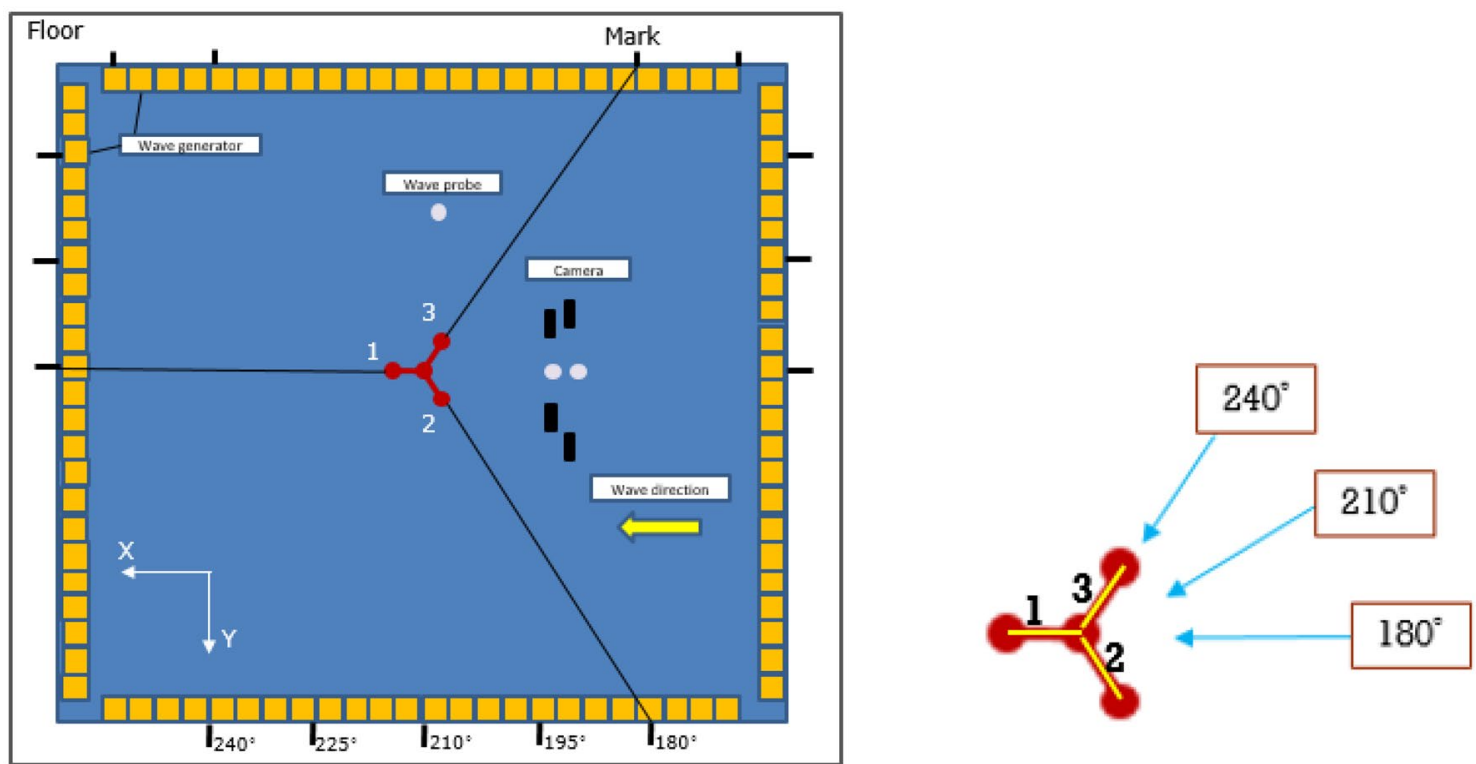

Fig. 6 Coordinate system in the experiment and arrangement of the model

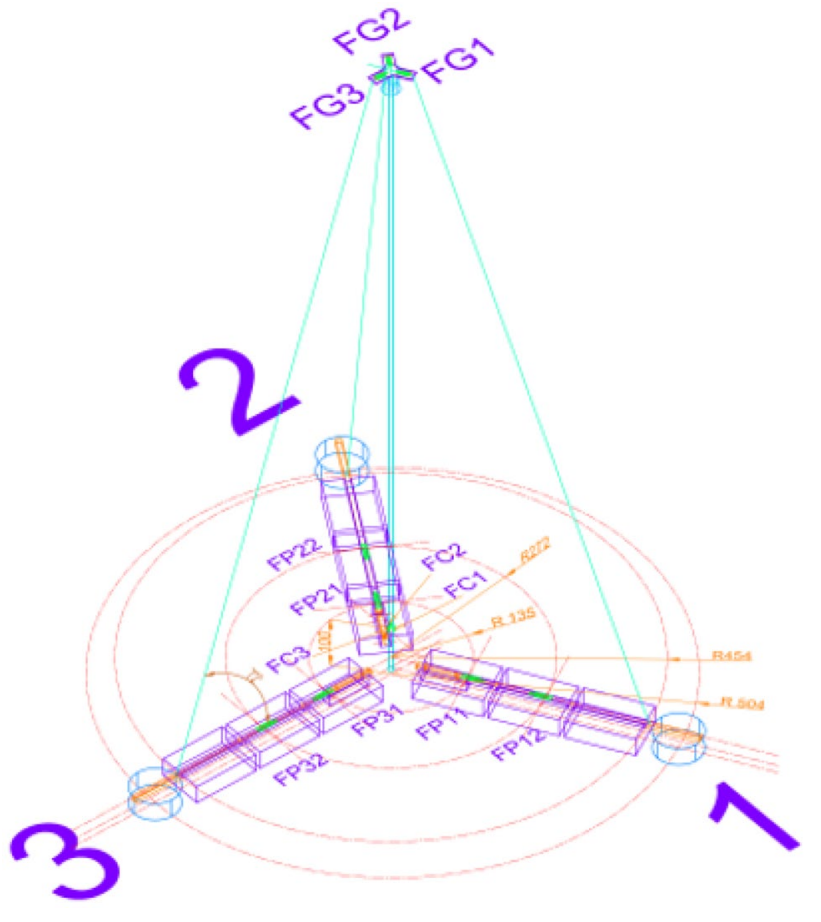

Fig. 7 Location of the strain gauge of the experiment model

(2) Irregular wave experiment

The irregular wave experiments were carried out for 4 cases. The experimental conditions in terms of real structure scale value are,

Case 1 JONSWAP: Hs: 2.5 m, Ts: $9.0 \mathrm{~s}$
Case 2 JONSWAP (storm condition): Hs: $9.8 \mathrm{~m}$, Ts: $13.5 \mathrm{~s}$

Case 3 JONSWAP: Hs: 4.0 m, Ts: $16.1 \mathrm{~s}$

Case 4 white noise: Hs: 2.0 m, Ts: 6.6-17.9 s

(3) Regular wave experiment

Regular wave experiments were carried out for 18 cases in total. In the 6 cases, experiments were carried out to see the effect of wave height on the heave motion. The wave frequency was fixed to the heave natural period of $16.35 \mathrm{~s}$ in terms of real structure scale, and the wave height was changed in the range of $0.5 \mathrm{~m}-6.0 \mathrm{~m}$. In the other 12 cases, the RAO was obtained from experiments in which the wave height was fixed $(1.5 \mathrm{~m})$ and the wave period was varied in the range of $6.0 \mathrm{~s}-17.0 \mathrm{~s}$.

\subsection{Experimental and numerical results}

1. Motion

Regular wave experiment (REG) result and white noise wave experiment result (WHI 01) for the case of the incident angle of $210^{\circ}$ are shown in Fig. 8. Calculation results by NK-UTWind, WAMIT and METiS-USP developed by University of San Paulo are also shown in the Fig. 8. Responses show typical response characteristics of a semi-submersible floater. Wave-free point is observed for heave motion calculated by WAMIT based on linear potential theory. The natural period of heave is $16.4 \mathrm{~s}$ and the natural period of pitch is $20.4 \mathrm{~s}$. A clear wave-free point is observed in measured pitch motion. The heave amplitude evaluated based on 

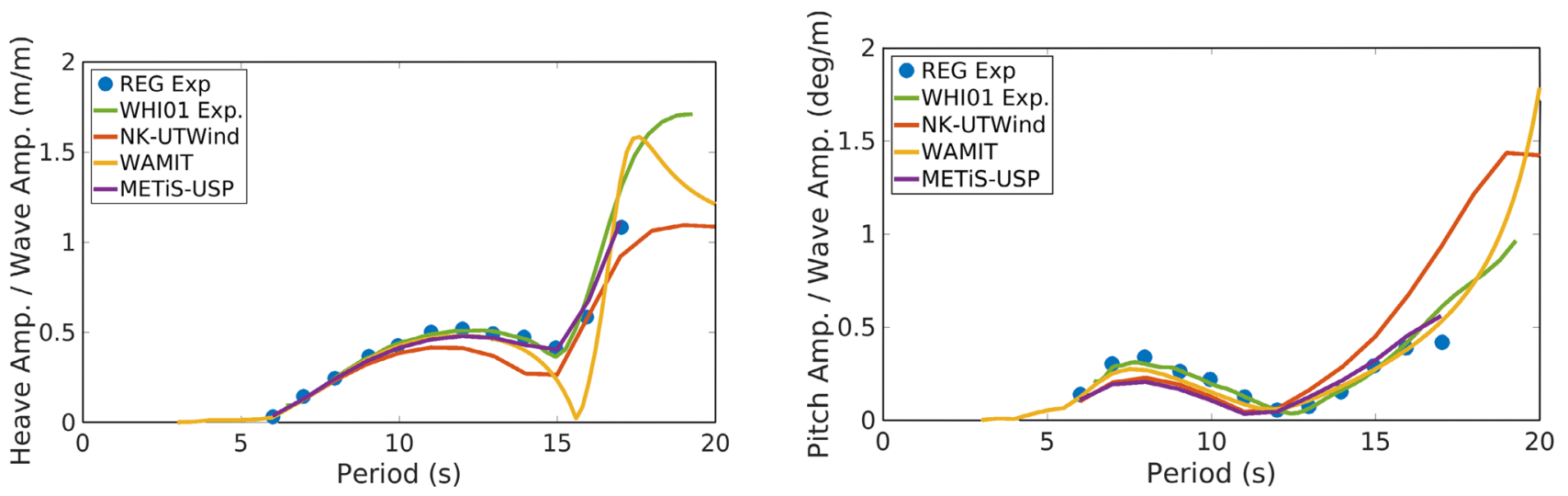

Fig. 8 Comparison of experiments and calculations of heave and pitch (REG regular wave experiment, WHI 01 white noise water wave experiment, NK-UTWind NK-UTWind calculation, WAMIT WAMIT calculation, METiS-USP METiS-USP calculation)

the results is $2.5 \mathrm{~m}$ for the storm condition with significant wave period of $13.5 \mathrm{~s}$ and significant wave height of $9.8 \mathrm{~m}$. The amplitude of pitch motion in the storm condition is $1^{\circ}$ and this value is very small.

\section{Consideration on tension fluctuation of guywire}

The initial tension of the guywire was set to $150 \mathrm{tf}$ in real structure scale, and it was confirmed that slack did not occur in the guywire through all the experimental conditions. Figure 9 shows the tension fluctuation amplitude of the guywire in the case of the incident wave angle of $180^{\circ}$ and $210^{\circ}$. It is observed that the peak of the tension amplitude coincides with the peak of the pitch motion.

In addition to the ratio of axial rigidity of the guywire to the rigidity of the frame structural part which determine load distribution to the guywire, pitch motion is also a dominant factor for the tension of guywire because load acting on the floating structure also depends on motion. At the wave period of $6 \mathrm{~s}$, pitch motion of the floating structure is small but oscillation frequency is high and the acceleration at the top of the tower is large. It causes large inertial force and makes tension fluctuation of guywire large. In the wave period $18 \mathrm{~s}$, the oscillation frequency is low and the acceleration is small, but the inclination of the floating structure is large. The overturning moment of tower caused by large inclination becomes large, and it makes tension fluctuation of guywire larger.

For the peaks of tension fluctuation, deformation by sagging and hogging load caused by heave motion needs to be considered further. It can be seen from the calculation by NK-UTWind that when the wave period is $6 \mathrm{~s}$, the phase difference between pitch and heave acceleration is approximately $180^{\circ}$. The superposition of the inertial force of RNA (rotor nacelle assembly) and tower makes the tension fluctuation of the guywire in the leeside larger. The tension fluctuation of guywire is also larger in leeside at the wave period of $18 \mathrm{~s}$.

Figure 10 shows the comparison between measured fluctuation of guywire tension and calculation result by
Fig. 9 Experimental result of guywire tension fluctuation (REG: Regular wave experiment, TRA: Transient wave experiment)
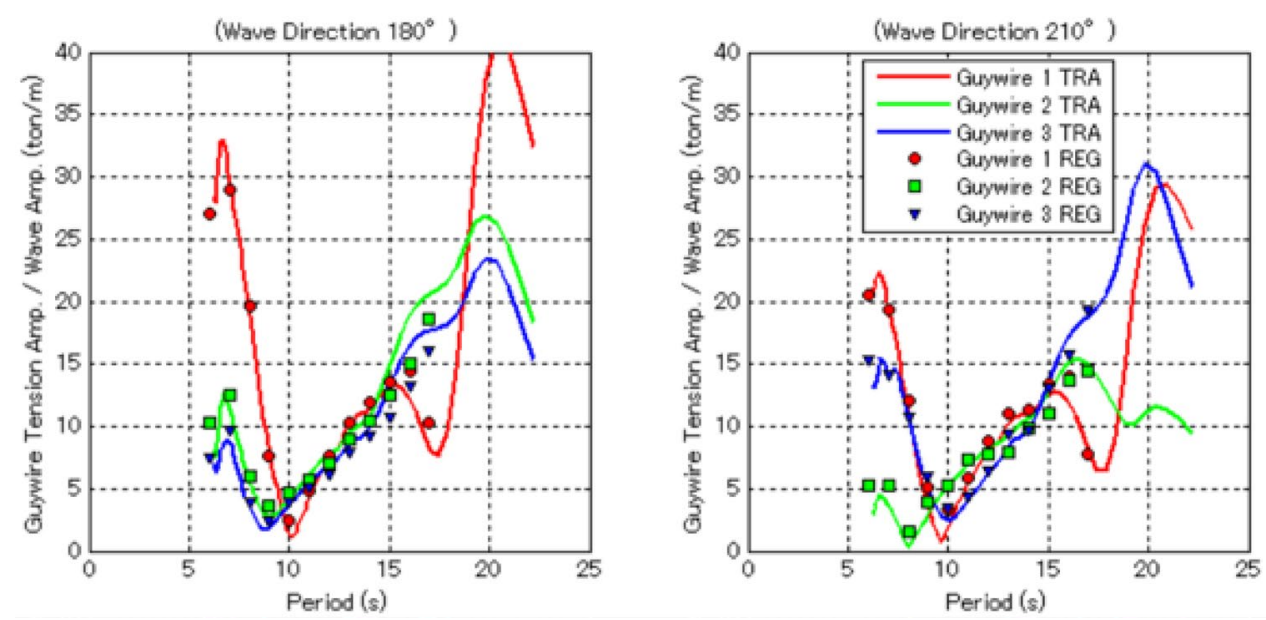
NK-UTWind in regular wave. The calculation result agreed well with the experimental value, and the validity of the tension calculation by NK-UTWind was confirmed in addition to the function of motion calculation.

Figure 11 shows the comparison of the guywire tension fluctuation calculated by NK-UTWind when the stiffness of the tower and pontoon is changed for the case of the incident wave angle of $180^{\circ}$. The tension fluctuation amplitudes when the rigidity of both tower and pontoon is low and cases either of tower or pontoon is lower are shown. As discussed based on the exact solution of static elastic model, it is understood that the tension fluctuation does not effectively reduced only by making either the tower or the pontoon rigid. The tension fluctuation is relatively smaller for the case with the rigid pontoon and flexible tower. It reflects the observation that the tension fluctuation decreases with increase of the pontoon rigidity by reducing deformation of sagging and hogging. At the wave period of $10 \mathrm{~s}$, the tension fluctuation amplitude takes minimum value. In the shorter wave period range than $10 \mathrm{~s}$, the tension amplitude is smaller for the case with rigid tower. For the longer wave period range than 10s, the tension amplitude is smaller with rigid pontoon.

3. Tower base strain

Figure 12 shows the experimental results of the strain at the tower base at the incident angles of $180^{\circ}, 210^{\circ}$ and $240^{\circ}$. The moment of the base of the tower is dominated by the pitch motion and peaks are observed around wave periods $6 \mathrm{~s}$ and $20 \mathrm{~s}$ similar to the guywire tension. Difference of the strains at the symmetrical positions with respect to the incident wave angle is observed. The difference is considered to be caused by a slight difference between the strain gauge attachment angle and the model installation direction.

For the longer wave period range than $10 \mathrm{~s}$, the tension amplitude is smaller with rigid pontoon.
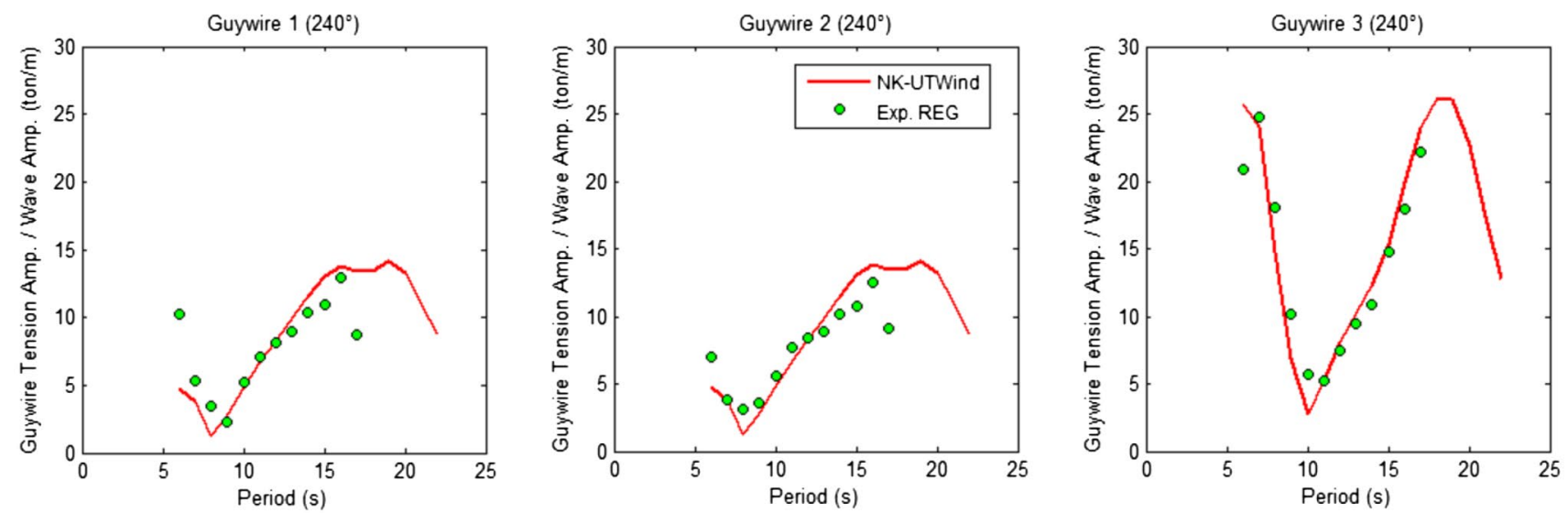

Fig. 10 Comparison between measured tension fluctuation and calculated tension fluctuation by NK-UTWind

Fig. 11 Influence of rigidity of tower and pontoon on guywire tension
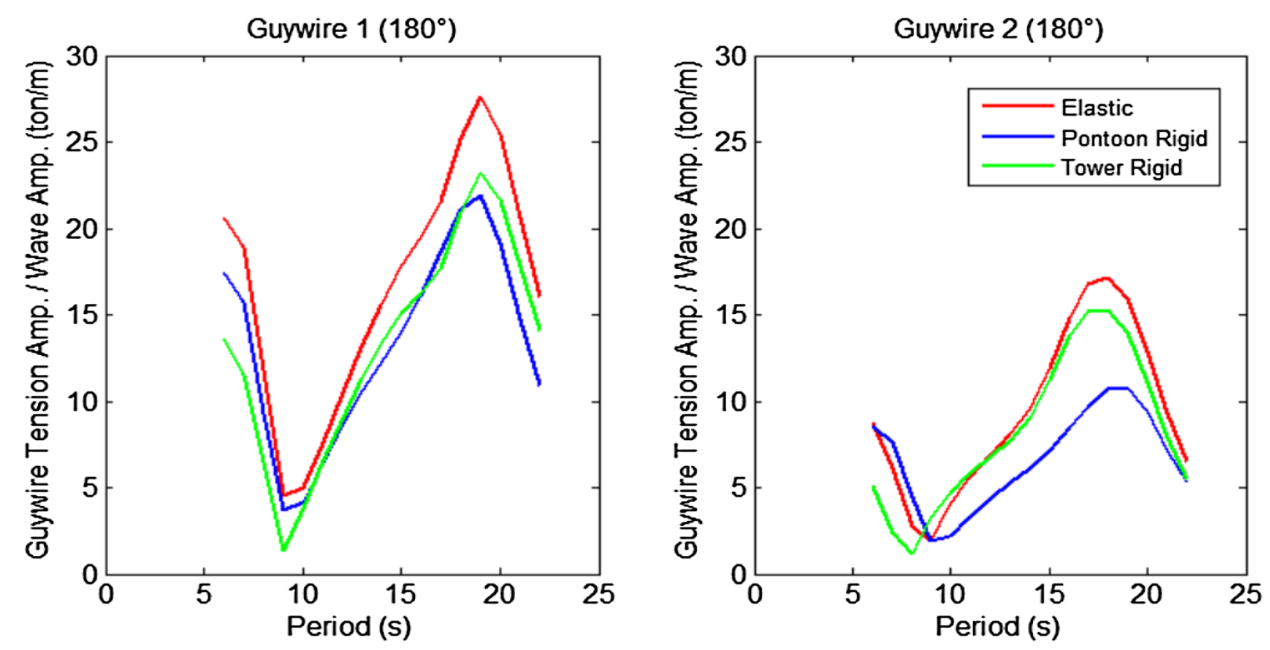

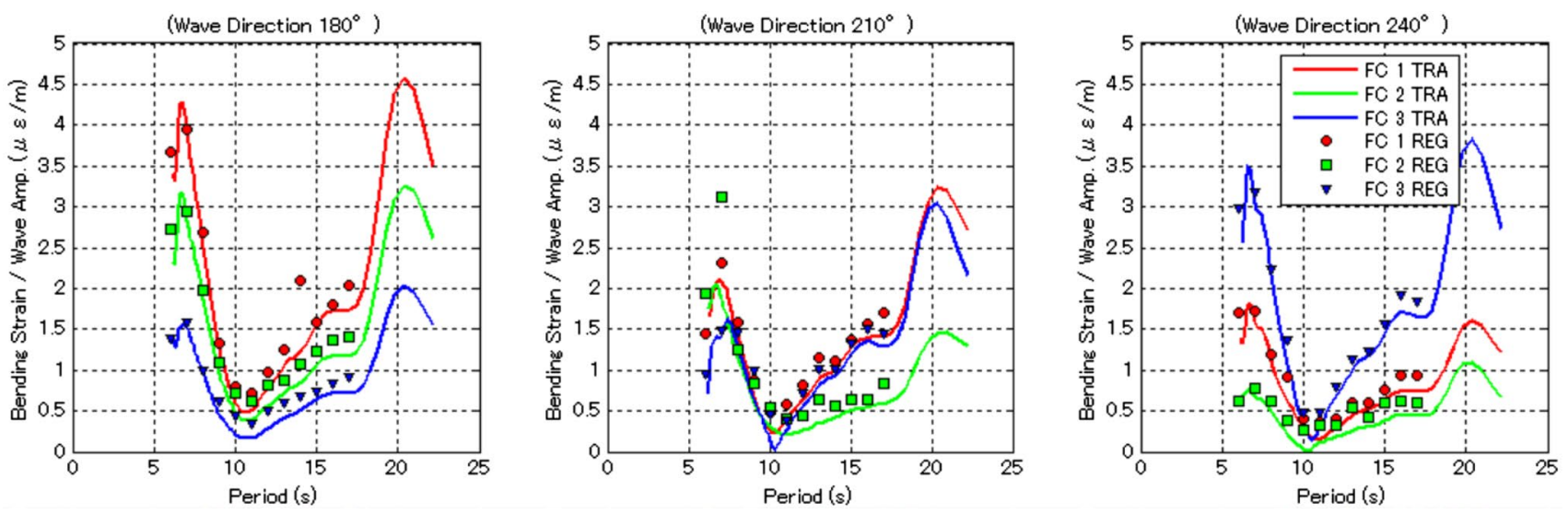

Fig. 12 Frequency response of bending strain obtained by experiment at the tower base (REG regular wave experiment, TRA transient wave experiment)

4. Pontoon strain at root and intermediate position

Figure 13 shows the strain at the base and intermediate position of the pontoon in the case of the incident angle of $180^{\circ}$. The influence of the heave motion appears strongly, and the strain FP11 at the root and strain FP12 at the intermediate position of the pontoon in the wave direction show a decrease around wave period of $17 \mathrm{~s}$. In both cases, a peak appears at a wave period of $20 \mathrm{~s}$. A peak appears at wave period $6 \mathrm{~s}$ for the root strain but it is not observed for the strain at intermediate position of pontoon.

\section{Elastic response of floating support structure with inclined tower}

Two designs of floating support structure with the inclined tower, Case 1 and Case 2, which are closer to the real structure were set based on the data of real floating support structure. They are shown in Figs. 14 and 15, respectively. Only the tower is inclined in Case 1 and columns are also inclined to point to the top of the tower in Case 2. Guywire 1 which connects bow and top of tower is longer than guywire 2 and 3 by $7 \mathrm{~m}$. As shown in the parameters regarding stability, GM is reduced by about $30 \%$ in Case 2 because the penetration position of the water surface is different and pitch natural period is longer in Case 2.

\subsection{Motion}

Motion of the three designs of floating support structure, generalized floating support structure, Case 1 and Case 2 were calculated by NK-UTWind. The calculated results in the case of incidence wave angle of $150^{\circ}$ are shown in Fig. 16. Heave and pitch show typical motion characteristics of semi-submersible type floating body. In Case 2, natural period of pitch and roll are longer, and pitch and roll motions are significantly smaller. Heave is also smaller at
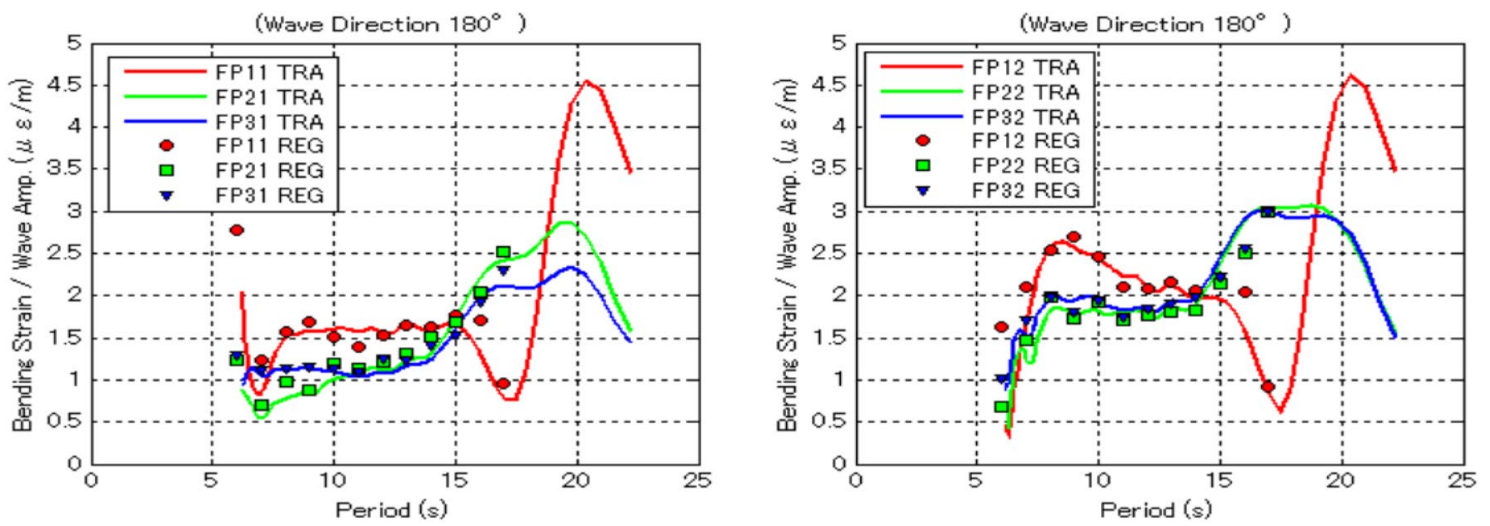

Fig. 13 Frequency response of bending strain at the root of pontoon (left) and intermediate position (right) obtained by experiment (REG: Regular wave experiment, TRA: Transient wave experiment) 
Fig. 14 Schematic diagram of Case 1 floating support structure and principal parameters related to stability

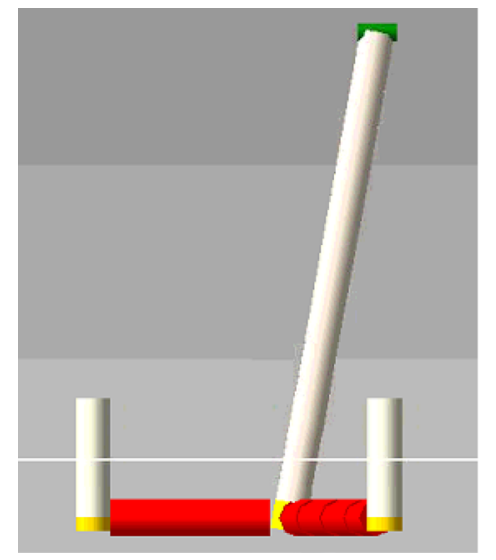

\begin{tabular}{|c|c|c|}
\hline Item & Value & Unit \\
\hline Displacement & 5784 & ton \\
\hline KB & 4.59 & $\mathrm{~m}$ \\
\hline BM & 16.05 & $\mathrm{~m}$ \\
\hline KG & 8.32 & $\mathrm{~m}$ \\
\hline GM & 12.33 & $\mathrm{~m}$ \\
\hline Natural Period of Heave & 15.2 & $\mathrm{sec}$ \\
\hline Natural Period of Roll and Pitch & 19.2 & $\mathrm{sec}$ \\
\hline
\end{tabular}

Fig. 15 Schematic diagram of Case 2 floating support structure and principal parameters related to stability

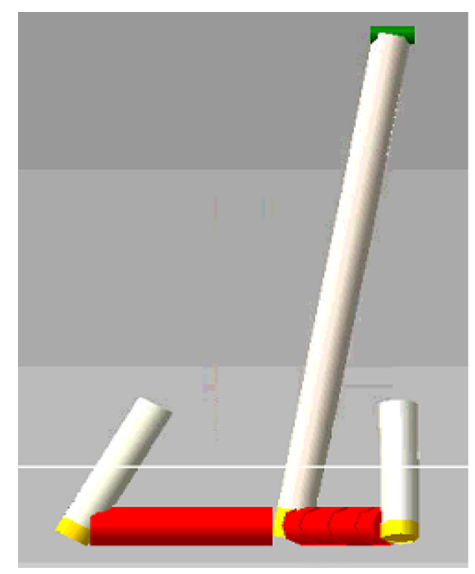

\begin{tabular}{|c|c|c|}
\hline Item & Value & Unit \\
\hline Displacement & 6024 & ton \\
\hline KB & 4.67 & $\mathrm{~m}$ \\
\hline BM & 11.53 & $\mathrm{~m}$ \\
\hline KG & 8.09 & $\mathrm{~m}$ \\
\hline GM & 8.10 & $\mathrm{~m}$ \\
\hline Natural Period of Heave & 15.0 & $\mathrm{sec}$ \\
\hline Natural Period of Roll and Pitch & 22.4 & $\mathrm{sec}$ \\
\hline
\end{tabular}

longer wave period compared with Case 1, and this is considered to contribute to make motions of Case 2 smaller. In long wave period, surge, sway and yaw are slightly larger in Case 1 and Case 2 than that of generalized floating support structure reflecting the difference of wave load acting on the columns.

\subsection{Tension fluctuating in guywire}

Figure 17 shows the fluctuation amplitude of guywire tension in the case of incident angle of $150^{\circ}$. Basically weight of the inclined tower is mainly supported by guywire 1 , and the largest tension fluctuation is observed in head sea and following sea. Pitching is the main cause of excitation of tension fluctuation of guywire 1. Pitch is the largest component of motion of floater in the case of incident wave angle of $150^{\circ}$ as shown in Fig. 16, and guywire 1 shows the largest tension fluctuation. The floater also experiences roll motion and tension fluctuations of guywire 2 and 3 are excited. The tension response of Case 2 which has smaller pitch motion in the wave period range of 10-20 s is much smaller compared with Case 1. The fluctuation range of the guywire tension of Case 1 is up to 33 ton/m per unit wave amplitude through all calculation conditions on the other hand the value is up to $19 \mathrm{ton} / \mathrm{m}$ for Case 2 . The range is up to $23 \mathrm{ton} / \mathrm{m}$ for the generalized support structure. The tension of the guywire of Case 1 sometimes exceeds the generalized model depending on the wave direction. Tension response is generally and remarkably reduced by the longer natural period of pitch of Case 2.

\section{Conclusion}

In this study, with the aim of obtaining fundamental knowledge on the motion characteristics and the elastic response of the design of a floating offshore wind turbine with guywire supported tower, a static structure model of the floating support structure is designed first. To have basic understanding on the load transmission by guywire and frame structure part, exact solution was obtained and investigated. The load supported by guywire is expressed as a function of ratio of guywire rigidity and rigidity of frame structural part. Dynamic response characteristics is investigated by wave tank experiments with dynamically and elastically similar 

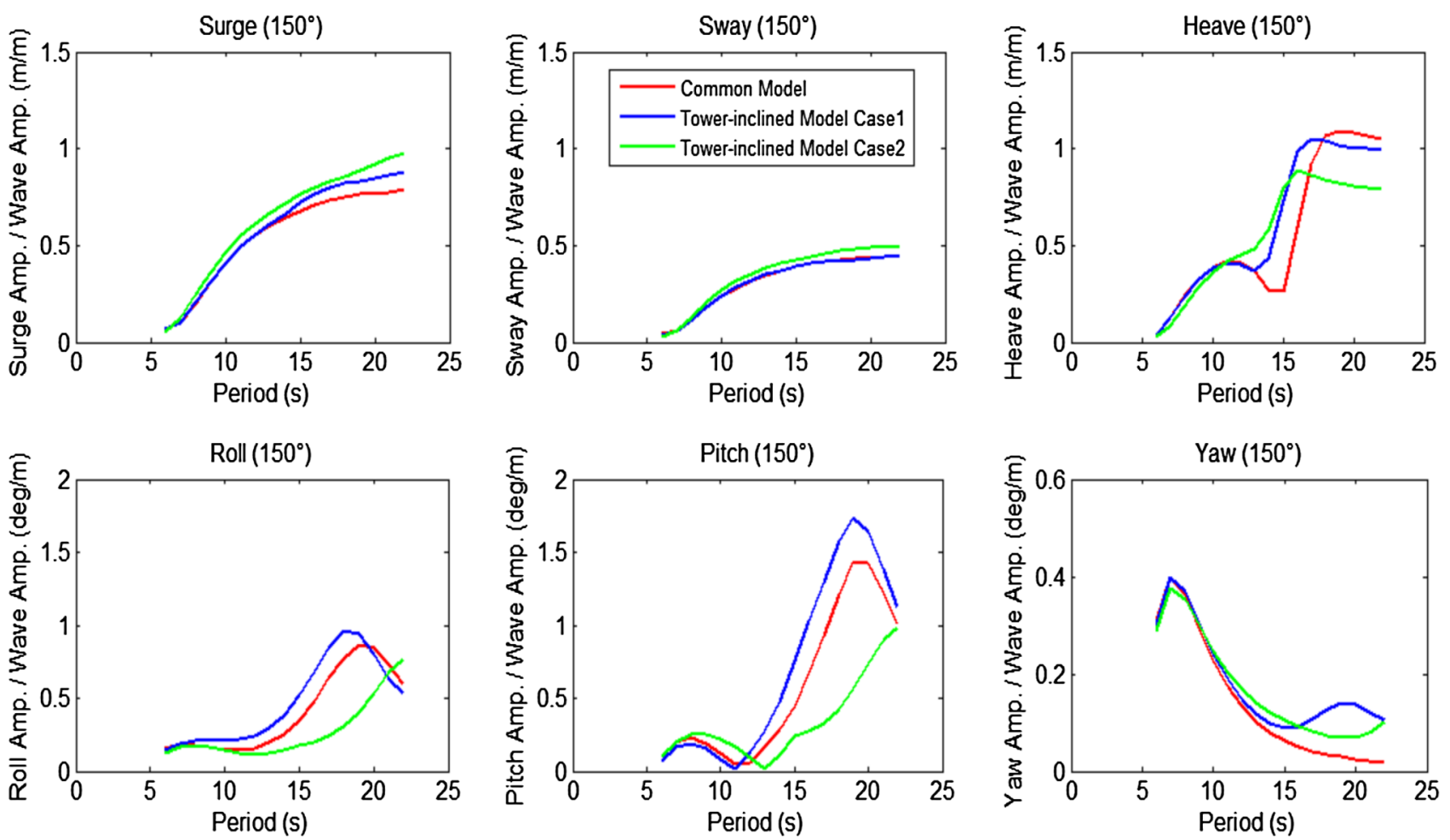

Fig. 16 RAO of motion of generalized floating support structure, Case 1 and Case 2 (incident wave direction $150^{\circ}$ )
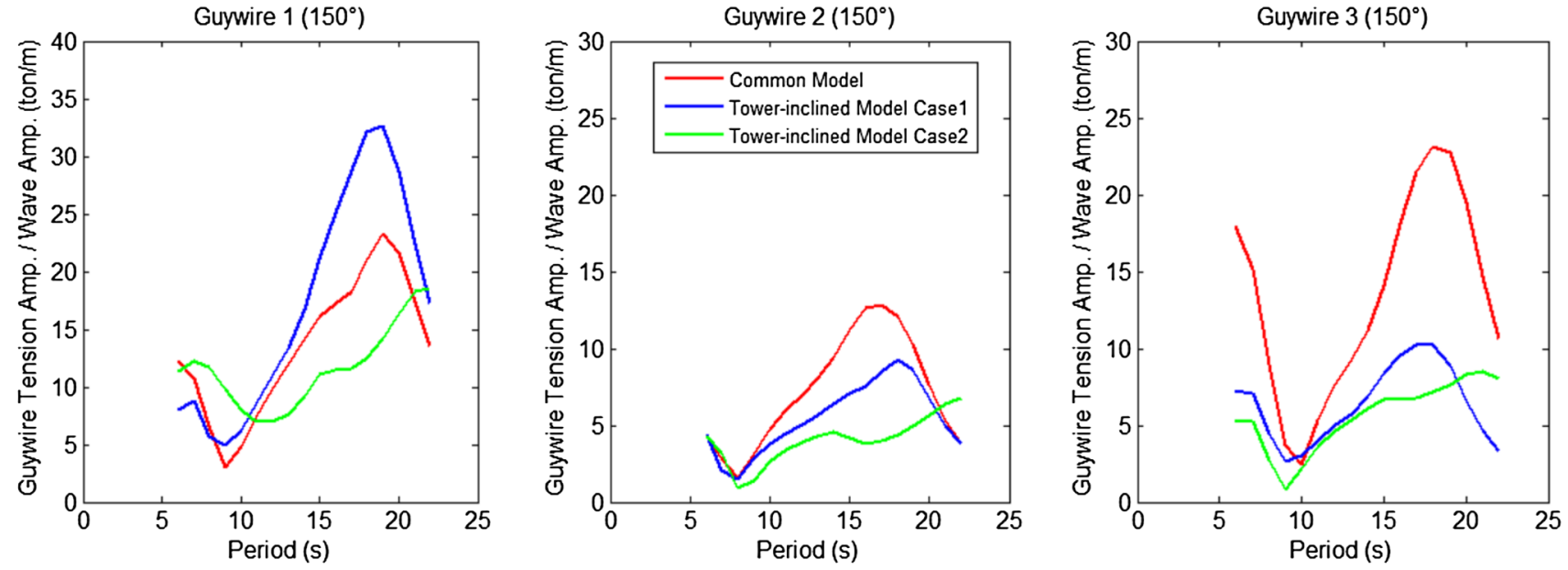

Fig. 17 RAO of guywire tension of generalized floating support structure, Case 1 and Case 2

segmented backbone model, and the response was analyzed by numerical codes.

Regarding investigation result on the static model, when the load supporting function is separately considered for guywire and the frame structural comprised of tower and pontoon, if the rigidity of the frame structural part is low, the load is mainly borne by guywire under pitch motion and on the contrary, when the rigidity of the frame structural part is large, the tension of the guywire becomes smaller. For heave motion, the effect of pontoon stiffness on the tension is seen. When the pontoon rigidity is large, the tension fluctuation of the guy wire becomes small.

Regarding the dynamic response, motion of the structure shows typical response characteristics of a semi-submersible 
type floating structure. As for the tension fluctuation of the guywire, it was found that the fluctuation becomes large at wave period of $6 \mathrm{~s}$ when the inertial force due to pitch motion is large, and at wave period of $18-20 \mathrm{~s}$ when inclination of tower is larger, the tension fluctuation also becomes large due to the overturning moment. Bending strain at the root of the pontoon increases at wave periods of $6 \mathrm{~s}$ and $18-20 \mathrm{~s}$, but no increase is observed at $6 \mathrm{~s}$ in the intermediate position of the pontoon.

Acknowledgements This research was conducted as part of the research project commissioned by New Energy and Industrial Technology Development Organization (NEDO) "Technological Research and Development of Wind Power Generation/Technological Research and Development of Offshore Wind Power Generation/Research and Demonstration Experiment of Next Generation Floating Offshore Wind Power Generation System (Development of Elemental Technologies)". The authors appreciate NEDO for allowing writing the paper.

Open Access This article is distributed under the terms of the Creative Commons Attribution 4.0 International License (http://creativeco mmons.org/licenses/by/4.0/), which permits unrestricted use, distribution, and reproduction in any medium, provided you give appropriate credit to the original author(s) and the source, provide a link to the Creative Commons license, and indicate if changes were made.

\section{Appendix 1: Guywire tension under horizontal force applied at tower top}

Based on the static structural model, the change of guywire tension from the initial equilibrium state is obtained as a function of horizontal external force applied at top of the tower.

\section{Basic relations}

\section{Deflection}

Considering the symmetry of the model, the elastic deflections at the both ends of the pontoon and the top of the tower are obtained from the beam theory as follows by removing the component due to the rigid body rotation.

$$
\begin{aligned}
& \delta_{1}-\delta+L \theta=\frac{L^{3}}{3 \mathrm{EI}}\left(\frac{H}{L_{G}} T_{1}-k_{\mathrm{B}} \delta_{1}\right), \\
& \delta_{2}-\delta-L \theta=\frac{L^{3}}{3 \mathrm{EI}}\left(\frac{H}{L_{\mathrm{G}}} T_{2}-k_{B} \delta_{2}\right), \\
& \Delta-H \theta=\frac{H^{3}}{3 \mathrm{EI}_{\mathrm{T}}}\left(\frac{L}{L_{\mathrm{G}}} T_{1}-\frac{L}{L_{\mathrm{G}}} T_{2}+F\right),
\end{aligned}
$$

where $L_{\mathrm{G}}=\sqrt{L^{2}+H^{2}}$.

\subsection{Guywire tension}

From the displacements at the both ends of the guywire, the guywire tensions are obtained as follows.

$T_{1}=k_{\mathrm{G}}\left\{-\frac{H}{L_{\mathrm{G}}}\left(\delta_{1}-\delta+L \theta\right)-\frac{L}{L_{\mathrm{G}}}(\Delta-H \theta)\right\}$,
$T_{2}=k_{\mathrm{G}}\left\{-\frac{H}{L_{\mathrm{G}}}\left(\delta_{2}-\delta-L \theta\right)+\frac{L}{L_{\mathrm{G}}}(\Delta-H \theta)\right\}$.

\section{Rigid body displacement}

Submersion of each column is changed by the action of horizontal external force, but sum of buoyancy is invariant. The overturning moment due to horizontal external force and restoring force induced by the change of buoyancy of each column is balanced. These conditions are given as follows.

$k_{B} \delta_{1}+k_{B} \delta_{2}+k \delta=0$
$-k_{B} L \delta_{1}+k_{B} L \delta_{2}-F H=0$

\section{Guywire tension due to horizontal force applied at tower top}

In the Eqs. (9-15), the seven parameters $\Delta, \delta_{1}, \delta_{2}, \delta, T_{1}, T_{2}$, $\theta$ are unknowns. Substituting the equations each other and eliminating the unknowns, the guywire tension is obtained as a function of the external horizontal force. Eliminating $\theta$ from (9) to (10), following expression is obtained.

$\delta_{1}+\delta_{2}-2 \delta=\frac{L^{3}}{3 E I}\left\{\frac{H}{L_{G}}\left(T_{1}+T_{2}\right)-k_{B}\left(\delta_{1}+\delta_{2}\right)\right\}$

Summing (12) and (13), an equation is obtained in which $\theta$ is eliminated. The equation and (14) are substituted into (16), and another equation in which $\delta_{1}$ and $\delta_{2}$ are eliminated is obtained as follows.

$-\left(\frac{k}{k_{\mathrm{B}}}+2\right) \delta=\frac{L^{3}}{3 \mathrm{EI}}\left\{k_{\mathrm{G}}\left(\frac{H}{L_{\mathrm{G}}}\right)^{2}\left(\frac{k}{k_{\mathrm{B}}}+2\right)+k\right\} \delta$.

Thus $\delta=0$ is obtained from (18), and the following relations are obtained from the Eqs. (12), (13), (14) and (15).

$\delta_{1}+\delta_{2}=0$

$T_{1}+T_{2}=0$,

$\delta_{1}=-\frac{F H}{2 k_{B} L}$. 
Substituting (9) and (11) into (12) and considering (18-20), guywire tension is obtained as a function of horizontal force applied at tower top.

$T_{1}=-\frac{\frac{L_{\mathrm{G}}}{2 L}}{\frac{1}{2 \frac{k_{\mathrm{G}}}{3 \mathrm{E} I_{\mathrm{T}}} \frac{H^{3} L^{2}}{L_{\mathrm{G}}^{2}}+\frac{k_{\mathrm{G}}}{3 \mathrm{El}} \frac{H^{2} L^{3}}{L_{\mathrm{G}}^{2}}}+1} F=-\frac{\frac{L_{G}}{2 L}}{\frac{1}{2 \frac{k_{\text {guywire }-t}}{k_{\text {tower }}}+\frac{k_{\text {guywire }}}{k_{\text {pontoon }}}}+1} F$,

where

Spring constant due to flexural rigidity of tower: $k_{\text {tower }}=\frac{3 \mathrm{EI}_{\mathrm{T}}}{H^{3}}$.

Horizontal spring constant by guy wire: $k_{\text {guywire }-t}=k_{\mathrm{G}}\left(\frac{L}{L_{\mathrm{G}}}\right)^{2}$.

Spring constant of pontoon against vertical force acting on pontoon tip: $k_{\text {pontoon }}=\frac{3 \mathrm{EI}}{L^{3}}$.

Vertical direction spring constant by guy wire: $k_{\text {guywire- } p}=k_{\mathrm{G}}\left(\frac{H}{L_{G}}\right)^{2}$.

\section{Appendix 2: Guywire tension under sagging and hogging force}

Guywire tension under sagging and hogging load due to wave is obtained.

\section{Basic relations}

As in Appendix 1, based on the static structural model, the change of guywire tension from the initial equilibrium state is obtained as a function of the external force. Considering the symmetry of the model, the deflections at the both ends of the pontoon are obtained from the beam theory as follows:

$\delta_{1}-\delta=\frac{L^{3}}{3 \mathrm{EI}}\left(\frac{H}{L_{\mathrm{G}}} T-k_{\mathrm{B}} \delta_{1}+F_{\mathrm{B}}\right)$,

$\delta_{1}-\delta=\frac{1}{2} \frac{L^{3}}{3 \mathrm{EI}}\left(2 \frac{H}{L_{\mathrm{G}}} T+k \delta-F\right)$,

where $L_{\mathrm{G}}=\sqrt{L^{2}+H^{2}}$. Multiplying $k$ and $2 k_{\mathrm{B}}$ on both sides of (22) and (23), respectively, and taking the difference of the equations, the following equation is obtained.

$\delta_{1}-\delta=\frac{\frac{L^{3}}{3 \mathrm{EI}}\left\{\frac{H}{L_{G}} T\left(k+2 k_{\mathrm{B}}\right)+k F_{\mathrm{B}}-k_{\mathrm{B}} F\right\}}{k+2 k_{\mathrm{B}}+k k_{\mathrm{B}} \frac{L^{3}}{3 \mathrm{EI}}}$.

\section{Guywire tension due to sagging and hogging force}

From the displacements at the both ends of the guywire, the guywire tension is obtained as follows.
$T=-k_{\mathrm{G}} \frac{H}{L_{\mathrm{G}}}\left(\delta_{1}-\delta\right)$.

From (24) and (25),

$T=-k_{\mathrm{G}} \frac{H}{L_{\mathrm{G}}} \frac{\frac{L^{3}}{3 \mathrm{EI}}\left\{\frac{H}{L_{G}} T\left(k+2 k_{\mathrm{B}}\right)+k F_{\mathrm{B}}-k_{\mathrm{B}} F\right\}}{k+2 k_{\mathrm{B}}+k k_{\mathrm{B}} \frac{L^{3}}{3 \mathrm{EI}}}$.

Therefore, guywire tension is obtained as a function of sagging and hogging Force.

$$
\begin{aligned}
T & =\frac{-k_{\mathrm{G}} \frac{H}{L_{\mathrm{G}}}\left(k F_{\mathrm{B}}-k_{\mathrm{B}} F\right)}{\left(\frac{k+2 k_{\mathrm{B}}}{\frac{L^{3}}{3 \mathrm{EI}}}+k k_{\mathrm{B}}+k_{\mathrm{G}}\left(\frac{H}{L_{\mathrm{G}}}\right)^{2}\left(k+2 k_{\mathrm{B}}\right)\right)} \\
& =\frac{-\frac{L_{\mathrm{G}}}{H}\left(\frac{k F_{\mathrm{B}}-k_{\mathrm{B}} F}{k+2 k_{\mathrm{B}}}\right)}{\frac{k_{\text {pontoon }}}{k_{\text {guywire }-p}}+\frac{k k_{B}}{\left(k+2 k_{\mathrm{B}}\right) k_{\text {guywire }-p}}+1} .
\end{aligned}
$$

\section{References}

1. http://www.fukushima-forward.jp/

2. http://goto-fowt.go.jp/

3. NEDO (1977) "Technological Research and Development of Wind Power Generation/Technological Research and Development of Offshore Wind Power Generation / Research and demonstration experiment of next generation floating offshore wind power generation system (Barge Type)“, Proceedings of Japan Society of Civil Engineers, No.257, pp123-126

4. http://www.aerodyn-engineering.com/scd-technology-scd-nezzy/

5. Yukio Maeda M, Hayashi, Maeda K (1977) Analytical calculation of sagging cable. J Jpn Soc Civ Eng 257:123-126

6. Jonkman JM (2007) Dynamics Modeling and Loads Analysis of an Offshore Floating Wind Turbine. Technical Report, NREL/ TP-500-41958,

7. Suzuki H, Shibata H, Fujioka H, Hirabayashi S, Ishii K, Kikuchi $\mathrm{H}$ Development of an analysis code of rotor-floater coupled response of a floating offshore wind turbine. In: 32th international conference on offshore mechanics and arctic engineering", OMAE2013-10444

8. Waris MB, Ishihara T (2012) Dynamic response analysis of floating offshore wind turbine with different types of heave plates and mooring systems by using a fully nonlinear model. Coupled Syst Mech 1(3):247-268

9. Lucie, Guignier et al (2016) Multibody modelling of floating offshore wind turbine foundation for global loads analysis. In: 26th International Ocean and polar engineering conference, Greece

10. https://nwtc.nrel.gov/OpenFAST

11. https://community.ieawind.org/task30/home

12. Robertson AN et al (2017) OC5 project phase II: validation of global loads of the DeepCwind floating semisubmersible wind turbine. Energy Proc 137:38-57 